\title{
Randomized trial of Cell Saver in 2- to 3-level lumbar instrumented posterior fusions
}

\author{
Mladen Djurasovic, MD, Katlyn E. McGraw, MPH, Kelly Bratcher, RN, CCRP, \\ Charles H. Crawford III, MD, John R. Dimar II, MD, Rolando M. Puno, MD, \\ Steven D. Glassman, MD, R. Kirk Owens II, MD, and Leah Y. Carreon, MD, MSc \\ Norton Leatherman Spine Center, Louisville, Kentucky
}

OBJECTIVE The goal of this study was to determine efficacy and cost-effectiveness of Cell Saver in 2- and 3-level lumbar decompression and fusion.

METHODS Patients seen at a tertiary care spine center who were undergoing a posterior 2- or 3-level lumbar decompression and fusion were randomized to have Cell Saver used during their surgery (CS group, $n=48$ ) or not used (No Cell Saver [NCS] group, $n=47$ ). Data regarding preoperative and postoperative hemoglobin and hematocrit, estimated blood loss, volume of Cell Saver blood reinfused, number of units and volume of allogeneic blood transfused intraoperatively and postoperatively, complications, and costs were collected. Costs associated with Cell Saver use were calculated based on units of allogeneic blood transfusions averted.

RESULTS Demographics and surgical parameters were similar in both groups. The mean estimated blood loss was similar in both groups: $612 \mathrm{ml}$ in the CS group and $742 \mathrm{ml}$ in the NCS group. There were $53 \mathrm{U}$ of allogeneic blood transfused in 29 patients in the NCS group at a total blood product cost of $\$ 67,688$; and $38 \mathrm{U}$ of allogeneic blood transfused in 16 patients in the CS group at a total blood cost of $\$ 113,162$, resulting in a cost of $\$ 3031$ per allogeneic blood transfusion averted using Cell Saver.

CONCLUSIONS Cell Saver use produced lower rates of allogeneic transfusion but was found to be more expensive than using only allogeneic blood for 2- and 3-level lumbar degenerative fusions. This increased cost may be reasonable to patients who perceive that the risks associated with allogeneic transfusions are unacceptable.

- CLASSIFICATION OF EVIDENCE Type of question: therapeutic; study design: randomized controlled trial; evidence: class III.

https://thejns.org/doi/abs/10.3171/2018.4.SPINE18116

KEYWORDS Cell Saver; lumbar fusion; blood management; blood transfusion; cost-effectiveness

I UMBAR spinal fusion is a commonly performed procedure for lumbar degenerative conditions. ${ }^{8}$ Lumbar and the optimal management of this blood loss continues to be debated. ${ }^{12}$ Although complications are rare with allogeneic transfusions, they can include allergic reactions, hemolytic reactions, isoimmunization, graft-versus-host reactions, and transmission of blood-borne pathogens. ${ }^{20}$ Various strategies have been devised to manage blood loss and replacement in spine surgery, in order to avoid possible complications of allogeneic blood transfusion. These include autologous predonation, hypotensive anesthesia, antifibrinolytics and recombinant human erythropoietin (rhEPO), and intraoperative and postoperative cell salvage systems such as Cell Saver.

The use of intraoperative cell salvage autotransfusion systems such as Cell Saver (Haemonetics Corp.) has become increasingly popular. Blood is collected via suction from the operative field, anticoagulated, filtered and then centrifuged to separate red blood cells from white blood cells, and then washed and reinfused into the patient. By reinfusing the patient's own blood, patients can receive autologous transfusion and avoid potential risks associated with allogeneic transfusion. The use of a cell salvage au-

ABBREVIATIONS ASA = American Society of Anesthesiologists; $\mathrm{BMI}=$ body mass index; $\mathrm{CS}=$ Cell Saver; NCS $=$ No Cell Saver; $\mathrm{RCT}=$ randomized controlled trial . SUBMITTED January 29, 2018. ACCEPTED April 9, 2018.

INCLUDE WHEN CITING Published online August 17, 2018; DOI: 10.3171/2018.4.SPINE18116. 


\section{- CLASSIFICATION OF EVIDENCE}

Type of Question Therapeutic

Study Design Randomized Controlled Trial

Evidence Class III

This class III randomized controlled trial (RCT) demonstrates a statistically significant reduction in transfusion requirements with the use of a Cell Saver device in patients undergoing 2or 3-level posterior lumbar fusions, but the reduction did not meet the prespecified criterion for a positive trial, and the cost was increased.

Classification of Evidence

The challenges of conducting an RCT are huge, and are even more daunting for surgical RCTs. Djurasovic and colleagues have successfully met these challenges with their study comparing transfusion requirements and costs in patients in whom Cell Saver technology was used to those findings in patients treated conventionally during 2- or 3-level lumbar posterior fusions. This is a monumental accomplishment, and the results of this trial are very informative. Despite its randomized design, and its adherence to most of the demands of a high-quality trial, some features of this study require some comment. Estimated blood loss was higher in the No Cell Saver (NCS) cohort compared to the Cell Saver (CS) group (mean difference $130 \mathrm{ml}[95 \% \mathrm{Cl} 34.5-294]$ ), and the majority of transfusions took place intraoperatively. In addition, the individuals responsible for deciding to use transfusion in study participants (the primary end point of the trial) were not masked to treatment assignment, and were not bound by study-imposed transfusion guidelines. These facts may have introduced a bias in favor of the CS group. The investigators also deserve praise for explicitly presenting the assumptions underlying their sample size calculation. The authors decided, a priori, that a reduction in the proportion of patients requiring transfusion from $50 \%$ (NCS) to $20 \%$ (CS), a $60 \%$ relative risk reduction, would be required for a "positive," or clinically important, study outcome. With a statistical significance of 0.05 and a power of $85 \%$, this required 46 patients in each treatment arm. Ultimately the study showed that $60 \%$ of patients in the NCS cohort and $34 \%$ of patients in the CS group required a transfusion (a relative risk reduction of $43 \%$, a relative risk of 1.74 [95\% Cl 1.15-2.63], and a number needed to treat of 4). The mean differences in allogeneic blood volume transfused (88.8 $\mathrm{ml}[95 \% \mathrm{Cl} 54.4-232], \mathrm{p}=0.68$ ) and number of units transfused $(0.31$ [ $95 \% \mathrm{Cl} 0.2-0.82], \mathrm{p}=0.61)$ were small and not statistically significant. The authors are enthusiastic about the potential role of Cell Saver in these neurosurgical procedures. In light of the potential for bias, the increased cost of the intervention (blood costs for the NCS vs CS cohorts were $\$ 67,688$ vs $\$ 113,162)$, and the less-than-hypothesized proportion of good outcomes (patients not requiring transfusion), a more circumspect conclusion might be appropriate. Further study is certainly warranted. Meanwhile, restricting the use of Cell Saver to carefully selected cases in which the typically very small risks of transfusion may be amplified (for example, patients with prior serious transfusion reactions, those with bleeding disorders, or those with the expectation of abnormally large blood loss) seems appropriate.

- Michael Glantz, MD
Hershey Medical Center
Hershey, Pennsylvania

totransfusion system has been studied extensively in other types of surgery, ${ }^{1,10,22}$ but studies of its use in spine surgery are limited, mostly retrospective, and have yielded conflicting results. Given the increased cost associated with the use of cell salvage, proper criteria for utilization of an autotransfusion system are still lacking and its use is controversial. ${ }^{2,5-7,9,15,17,19}$

A significant limitation of prior research regarding Cell Saver has been the nonrandomized, retrospective nature of these studies and the potential for selection bias. Given that surgeons probably choose to use Cell Saver in cases with higher anticipated blood loss, and choose not to use it when blood loss is expected to be low, retrospective comparisons of nonrandomized Cell Saver (CS) and No Cell Saver (NCS) cohorts will have significant limitations. Although controversial, previous work has suggested that Cell Saver is not cost-effective when used in single-level lumbar fusions, ${ }^{4}$ but that it may be cost-effective when used in cases with higher anticipated blood loss such as multilevel lumbar fusion. ${ }^{13}$ In the current study, we used a prospective randomized controlled trial (RCT) to study the efficacy and cost-effectiveness of Cell Saver for 2- and 3-level lumbar degenerative fusions based on units of allogeneic blood transfusions averted.

\section{Methods}

After the study received institutional review board approval, patients undergoing elective lumbar fusion at our center were screened for inclusion in this prospective, open-label RCT. Inclusion criteria were patients over 18 years of age, scheduled to have a 2- or 3-level lumbar decompression and fusion between L1-S1 through a posterior-only approach by their treating surgeon, for symptomatic degenerative lumbar disease, including spinal stenosis with instability, spondylolisthesis, revision decompression, or adjacent-segment disease. Patients undergoing fusion for tumor, trauma, infection, or nondegenerative pathology were excluded. Prisoners, institutionalized patients who may not be competent to give informed consent, and nonEnglish speakers were also excluded.

A sample size of 46 subjects in each group was determined based on the hypothesis that the use of Cell Saver will reduce the need for allogeneic transfusions to $20 \%$ of patients from $50 \%$, at an $\alpha$ of 0.05 , with a power of 0.85 . Randomization was performed with stratified block randomization in blocks of 6 to allow for stratification of the number of levels fused by using sealed envelopes. Patients were not informed of randomization results, but the surgeon was informed. Prior to surgery, basic demographic data were collected including age, sex, smoking status, height, weight, comorbidities, and use of medica- 




FIG. 1. Consolidated Standards for Reporting of Trials (CONSORT) flowchart.

tions that may affect bleeding (anticoagulants, antiinflammatory medications).

Intraoperative data were collected including number of levels fused, estimated blood loss, use of interbody fusion (e.g., transforaminal lumbar interbody fusion), harvesting of iliac crest bone graft, and the occurrence of intraoperative complications. In the CS group, the volume of blood collected and reinfused was recorded. Any intraoperative allogeneic transfusions and the volume of blood transfused were also recorded. Postoperatively, the need for allogeneic transfusion was left to the discretion of the treating surgeon, but was generally triggered by a hemoglobin level of less than $8.0 \mathrm{~g} / \mathrm{dl}$, associated with hypotension, tachycardia, or existing cardiac disease. Volume of transfusion was recorded, as was hematocrit and hemoglobin, daily until postoperative day 7 .

The costs of setting up the blood salvage machine, infusing salvaged autologous blood, and transfusing allogeneic blood were obtained from billing representatives at our institution. The cost of setting up Cell Saver during surgery was $\$ 313$, and the cost of using Cell Saver to reinfuse autologous blood was $\$ 1699$. The cost of allogeneic blood was $\$ 1060$ per unit plus a one-time charge of $\$ 411$ to run initial screening tests. All costs are given in 2016 US dollars.

The CS and NCS cohorts were compared with respect to hemoglobin, hematocrit, and the need for allogeneic transfusion. All statistical analyses were conducted using IBM SPSS Statistics version 20 (IBM Corp.), with the significance level set at $\mathrm{p}<0.05$. The independent-samples $\mathrm{t}$-test was used to determine any significant differences in continuous variables between groups, and the Fisher exact test was used to compare categorical variables between the groups.

\section{Results}

Of 115 subjects enrolled in the study, 95 were included in the analysis (Fig. 1). Subjects were excluded due to surgery being cancelled (9), withdrawal of the subject from the study ( 2 in each cohort), change of surgical approach (3 in each cohort), or change of procedure to a single-level surgery ( 5 in each cohort). There were 47 subjects in the NCS and 48 in the CS group. The 2 cohorts were similar in age, sex distribution, body mass index (BMI), smoking status, and indication for surgery (Table 1). There was also no statistically significant difference in American Society of Anesthesiologists (ASA) grade, number of levels fused, or number of interbody fusions between the NCS and CS groups. The estimated blood loss and operating time were similar between the 2 groups as well (Table 2).

Preoperative and postoperative day 1 hematocrit and hemoglobin levels between the groups were similar (Table 3 ). The Cell Saver machine was available in 12 cases in the CS group, but the blood collected was not processed or reinfused-the volume of fluid collected in the Cell Saver reservoir needs to be at least $250 \mathrm{ml}$ to be processed. The proportion of patients not requiring an allogeneic blood transfusion was statistically significantly greater in the CS group (66\%) compared to the NCS group (38\%). Of the 
TABLE 1. Summary of demographic data

\begin{tabular}{lccc}
\hline \multicolumn{1}{c}{ Clinical Characteristics } & NCS & CS & p Value \\
\hline No. of patients & 47 & 48 & \\
\hline No. of males & 17 & 20 & 0.583 \\
\hline No. of smokers & 5 & 9 & 0.283 \\
\hline Age, yrs; mean (SD) & $61.8(11.4)$ & $62.9(10.6)$ & 0.657 \\
\hline BMl, kg/m²; mean (SD) & $32.4(8.3)$ & $32.1(6.7)$ & 0.301 \\
\hline No. w/ diagnosis & & & 0.267 \\
\hline \multicolumn{1}{c}{ Spondylolisthesis } & 19 & 24 & \\
\hline Stenosis & 25 & 17 & \\
\hline Scoliosis & 0 & 2 & \\
\hline Adjacent-segment disease & 2 & 2 & \\
\hline Post-discectomy & 1 & 3 & \\
\hline
\end{tabular}

subjects requiring an allogeneic transfusion, the volume of blood transfused was similar between the 2 groups. The number of units of allogeneic blood transfused was smaller in the CS group compared to the NCS group, but this was not statistically significantly different.

Considering the cost of setting up and reinfusing the blood collected in the Cell Saver machine as well as the cost of allogeneic blood transfusions, the use of Cell Saver leads to higher mean total blood costs (\$2357) compared to not using the machine (\$1440). If costs and number of allogeneic blood transfusions for the entire cohort are considered (Table 4), the use of Cell Saver averted the use of $15 \mathrm{U}$ of allogeneic blood at a difference in cost of $\$ 45,474$. This leads to a cost of $\$ 3031$ per allogeneic blood unit transfusion averted.

\section{Discussion}

Our study is the first prospective RCT to examine the efficacy and cost-effectiveness of intraoperative blood salvage using Cell Saver during lumbar degenerative fusions. Previous retrospective research has found that Cell Saver probably is not cost-effective for 1-level fusion ${ }^{4}$ or in cases with blood loss less than $500 \mathrm{ml},{ }^{13}$ but may be cost-effective in cases with blood loss greater than $600 \mathrm{ml} .{ }^{11}$ Thus we chose to limit inclusion criteria to 2- and 3-level fusions, in which higher blood loss was anticipated. We found that the use of intraoperative Cell Saver leads to a reduction in the frequency of allogeneic transfusion, as well as the total number of allogeneic blood units transfused.

The use of Cell Saver led to higher total blood product costs in the CS cohort. In the CS cohort, a total of \$113,162 was spent on a combination of allogeneic transfusion, Cell Saver set-up costs, and Cell Saver reinfusion costs. In the NCS cohort, $\$ 67,688$ was spent on allogeneic transfusion alone. Thus, Cell Saver use cost $\$ 3031$ per unit of allogeneic blood transfusion averted, which is slightly more costly than transfusion of a unit of allogeneic blood, which in our institution averages $\$ 1471$. The use of Cell Saver has a negligible complication rate, whereas allogeneic transfusion has a small but real risk of disease transmission and adverse events. In addition, some patients may be averse to blood transfusion, or have medical comorbidities or re-
TABLE 2. Summary of surgical data

\begin{tabular}{lccc}
\hline \multicolumn{1}{c}{ Surgical Characteristics } & NCS & CS & p Value \\
\hline No. of patients & 47 & 48 & \\
\hline ASA grade & & & 0.150 \\
\hline 2 & 4 & 11 & \\
\hline 3 & 40 & 35 & \\
\hline 4 & 3 & 2 & \\
\hline No. of levels fused & \multicolumn{3}{c}{0.424} \\
\hline 2 & 41 & 39 & \\
\hline 3 & 6 & 9 & 0.207 \\
\hline No. of TLIF levels & 5 & 9 & \\
\hline 1 & 6 & 2 & 0.193 \\
\hline 2 & 44 & 41 & 0.120 \\
\hline ICBG & $741.8(418.7)$ & $611.8(387.9)$ & \\
\hline Estimated blood loss, ml; & & & \\
$\quad$ mean (SD) & $249.5(74.7)$ & $266.4(67.6)$ & 0.262 \\
\hline Op time, minutes; mean (SD) & & & \\
\hline
\end{tabular}

ICBG = iliac crest bone graft; TLIF = transforaminal lumbar interbody fusion.

ligious beliefs that make allogeneic transfusion less than ideal. ${ }^{20}$ Thus, Cell Saver may be a reasonable added expense to consider in multilevel lumbar fusions, where the additional cost represents a small relative cost compared to the entire episode of care.

Cell Saver will have its greatest utility in surgical cases in which blood loss will be high and the chance of allogeneic transfusion significant. Surgeons have intuitively applied this guideline with respect to its use. Cell Saver is rarely used for lumbar discectomy and decompression procedures, in which transfusion is very unusual; it is much more routinely used in pediatric and adult deformity surgeries, in which blood loss often exceeds $1000 \mathrm{ml}$ and multiple blood management strategies are often used. Fusions done for lumbar degenerative disease are an intermediate clinical situation, in which blood loss is variable and indications for Cell Saver use are less well defined.

At one end of the spectrum, Canan et al. retrospectively studied the cost-effectiveness of Cell Saver for single-level instrumented lumbar fusion and found it not to be costeffective. ${ }^{4}$ In this clinical scenario, the authors saw no decrease in the need for allogeneic transfusion with the use of Cell Saver. Because there was no difference in transfusion rates between their Cell Saver cohort and controls, their modeled incremental cost-effectiveness ratio (ICER) was calculated to be more than $\$ 5,000,0000$. Interestingly, Owens et al..$^{18}$ studied which factors predict the use of Cell Saver in lumbar degenerative fusion and found that multilevel fusion was a predictor of voluntary use of Cell Saver. This would suggest that clinicians may be doubtful about the utility of Cell Saver in simple single-level fusions, but may believe it is more useful in multilevel fusions.

In contrast, multiple studies have found Cell Saver to be effective in decreasing transfusion requirements in scoliosis surgery. Liang et al. recently reported a prospective RCT for the use of Cell Saver in adolescent idiopathic scoliosis surgery. ${ }^{14}$ They randomized 110 consecutive patients with scoliosis with respect to the use of Cell Saver, 
TABLE 3. Summary of hematological and blood management data

\begin{tabular}{lccc}
\hline \multicolumn{1}{c}{ Hematological Data } & NCS & CS & p Value \\
\hline No. of patients & 47 & 48 & 0.463 \\
\hline Preop hematocrit, \%; mean (SD) & $40.2(7.4)$ & $41.4(3.0)$ & 0.864 \\
\hline Preop hemoglobin, g/dl; mean (SD) & $14.0(1.6)$ & $13.9(1.2)$ & 0.478 \\
\hline Postop day 1 hematocrit, \%; mean (SD) & $31.9(3.6)$ & $32.5(4.2)$ & 0.463 \\
\hline Postop day 1 hemoglobin, g/dl; mean (SD) & $10.5(1.2)$ & $10.7(1.5)$ & 0.78 \\
\hline Max temperature during admission, ${ }^{\circ}$ F; mean (SD) & $99.7(0.9)$ & $100.0(0.9)$ & 36 \\
\hline No. w/ Cell Saver blood processed \& reinfused & NA & $205.6(174.6)$ & 0.007 \\
\hline Cell Saver blood vol reinfused, ml; mean (SD) & NA & $32(66 \%)$ & 16 \\
\hline Transfusion, no. (\%) of patients & $18(38 \%)$ & 12 & 0.682 \\
\hline No transfusion & 29 & 7 & 0.612 \\
\hline Transfused intraop or postop & 22 & $228.6(380.3)$ & 0.008 \\
\hline Transfused intraop & 11 & $0.79(1.3)$ & $\$ 2357$ \\
\hline Transfused postop & $317.4(320.1)$ & & \\
\hline Allogeneic blood vol transfused, ml; mean (SD) & $1.1(1.2)$ & $\$ 1440$ & \\
\hline No. of allogeneic blood units transfused; mean (SD) & & \\
\hline Actual total blood costs, \$US; mean & & & \\
\hline
\end{tabular}

Max = maximum; $N A=$ not applicable.

${ }^{*}$ Blood units $=280 \mathrm{ml} / \mathrm{U}$.

and found that Cell Saver decreased the incidence of allogeneic transfusion from $32.7 \%$ to $14.5 \%$. As might be expected, the number of levels fused was an independent risk factor for the need for transfusion. In retrospective studies, Miao et al. ${ }^{16}$ and Bowen et al. ${ }^{3}$ also found that Cell Saver decreased the incidence of allogeneic transfusion..$^{16}$ Stone et al. conducted a systematic review of the literature on Cell Saver use in adolescent idiopathic scoliosis. ${ }^{21}$ They found that when the data from 7 eligible studies were combined, Cell Saver decreased the incidence of perioperative transfusion by $47 \%$, and recommended its use in surgery for adolescent scoliosis.

Our trial examined the clinical utility of Cell Saver for an intermediate clinical scenario with respect to blood loss, between single-level fusion and multilevel deformity surgery-namely 2- and 3-level lumbar fusion. Our study found that Cell Saver use decreased the incidence of allogeneic transfusion. Only one other study has examined use of Cell Saver in 2- and 3-level lumbar fusion. Kelly and coworkers $^{13}$ did a retrospective cost-effectiveness study of Cell Saver in 2- and 3-level lumbar decompression and fusion. They found that Cell Saver was not cost-effective in their overall study sample. However, because their study was retrospective and nonrandomized, they found significant differences in their Cell Saver cohort compared to controls. Patients selected for Cell Saver use in this study had higher anticipated blood loss based on higher BMI and greater ASA score for preoperative medical comorbidities, and they were more likely to be undergoing revision surgery. Kelly et al. found that Cell Saver would probably reach the threshold for cost-effectiveness in cases in which blood loss exceeds $500 \mathrm{ml}$. A more recent study by Gum et al. ${ }^{11}$ in patients with adult spinal deformity showed that Cell Saver use was not cost-effective in general, but that it may be cost-effective in cases in which blood loss was greater than $614 \mathrm{ml}$. Interestingly, the estimated blood loss in both CS and NCS cohorts in our study were greater than this 500-ml threshold.

Our study has several limitations. Our sample size was relatively small. Also, cost-effectiveness calculations were based on avoidance of transfusion only. True measures of quality-adjusted life years gained by avoidance of transfusion are estimates only, and are not universally agreed upon. The decision to transfuse postoperatively did not adhere to strict guidelines based on patient symptomatology or hemoglobin levels. The costs cited in this study are specific to the institution and to the CS technology used, and may not be directly generalizable to other institutions and technologies.

\section{Conclusions}

This study shows that when Cell Saver is used in 2and 3-level lumbar degenerative fusions, it leads to a decrease in the rate of allogeneic transfusion. Although total blood costs are somewhat increased, the decrease in perioperative allogeneic transfusion leads to Cell Saver being a potentially reasonable additional cost in this clinical scenario. Use of Cell Saver should be considered in 2- and 3-level lumbar degenerative fusion procedures in which significant blood loss is anticipated. Future re-

TABLE 4. Cost-effectiveness data

\begin{tabular}{lccc}
\hline \multicolumn{1}{c}{ Cost Data } & NCS & CS & Difference \\
\hline $\begin{array}{l}\text { Total no. of allogeneic units } \\
\text { transfused }\end{array}$ & 53 & 38 & 15 \\
\hline $\begin{array}{l}\text { Total allogeneic blood transfusion } \\
\text { costs }\end{array}$ & $\$ 67,688$ & $\$ 44,325$ & \\
\hline Total Cell Saver cost & $\$ 0$ & $\$ 68,837$ & \\
\hline Blood cost for entire cohort & $\$ 67,688$ & $\$ 113,162$ & $\$ 45,474$ \\
\hline
\end{tabular}


search should focus on predictive models, which incorporate more detailed patient characteristics, to better define appropriate clinical use criteria for intraoperative cell salvage.

\section{References}

1. Ashworth A, Klein AA: Cell salvage as part of a blood conservation strategy in anaesthesia. Br J Anaesth 105:401-416, 2010

2. Behrman MJ, Keim HA: Perioperative red blood cell salvage in spine surgery. A prospective analysis. Clin Orthop Relat $\operatorname{Res}(278): 51-57,1992$

3. Bowen RE, Gardner S, Scaduto AA, Eagan M, Beckstead J: Efficacy of intraoperative cell salvage systems in pediatric idiopathic scoliosis patients undergoing posterior spinal fusion with segmental spinal instrumentation. Spine (Phila Pa 1976) $35: 246-251,2010$

4. Canan CE, Myers JA, Owens RK, Crawford CH III, Djurasovic $\mathrm{M}$, Burke LO, et al: Blood salvage produces higher total blood product costs in single-level lumbar spine surgery. Spine (Phila Pa 1976) 38:703-708, 2013

5. Cavallieri S, Riou B, Roche S, Ducart A, Roy-Camille R, Viars P: Intraoperative autologous transfusion in emergency surgery for spine trauma. J Trauma 36:639-643, 1994

6. Cha CW, Deible C, Muzzonigro T, Lopez-Plaza I, Vogt M, Kang JD: Allogeneic transfusion requirements after autologous donations in posterior lumbar surgeries. Spine (Phila Pa 1976) 27:99-104, 2002

7. Chanda A, Smith DR, Nanda A: Autotransfusion by cell saver technique in surgery of lumbar and thoracic spinal fusion with instrumentation. J Neurosurg 96 (3 Suppl):298-303, 2002

8. Deyo RA, Gray DT, Kreuter W, Mirza S, Martin BI: United States trends in lumbar fusion surgery for degenerative conditions. Spine (Phila Pa 1976) 30:1441-1447, 2005

9. Gause PR, Siska PA, Westrick ER, Zavatsky J, Irrgang JJ, Kang JD: Efficacy of intraoperative cell saver in decreasing postoperative blood transfusions in instrumented posterior lumbar fusion patients. Spine (Phila Pa 1976) 33:571-575, 2008

10. Goulet JA, Bray TJ, Timmerman LA, Benson DR, Bargar WL: Intraoperative autologous transfusion in orthopaedic patients. J Bone Joint Surg Am 71:3-8, 1989

11. Gum JL, Carreon LY, Kelly MP, Hostin R, Robinson C, Burton DC, et al: Cell saver for adult spinal deformity surgery reduces cost. Spine Deform 5:272-276, 2017

12. Johnson RG, Murphy M, Miller M: Fusions and transfusions. An analysis of blood loss and autologous replacement during lumbar fusions. Spine (Phila Pa 1976) 14:358-362, 1989

13. Kelly PD, Parker SL, Mendenhall SK, Bible JE, Sivasubramaniam P, Shau DN, et al: Cost-effectiveness of Cell Saver in short-segment lumbar laminectomy and fusion ( $\leq 3$ levels). Spine (Phila Pa 1976) 40:E978-E985, 2015

14. Liang J, Shen J, Chua S, Fan Y, Zhai J, Feng B, et al: Does intraoperative cell salvage system effectively decrease the need for allogeneic transfusions in scoliotic patients undergoing posterior spinal fusion? A prospective randomized study. Eur Spine J 24:270-275, 2015

15. Mann DC, Wilham MR, Brower EM, Nash CL Jr: Decreasing homologous blood transfusion in spinal surgery by use of the cell saver and predeposited blood. Spine (Phila Pa 1976) 14:1296-1300, 1989

16. Miao YL, Ma HS, Guo WZ, Wu JG, Liu Y, Shi WZ, et al: The efficacy and cost-effectiveness of cell saver use in instrumented posterior correction and fusion surgery for scoliosis in school-aged children and adolescents. PLoS One 9:e92997, 2014

17. Nuttall GA, Horlocker TT, Santrach PJ, Oliver WC Jr, Dekutoski MB, Bryant S: Predictors of blood transfusions in spinal instrumentation and fusion surgery. Spine (Phila Pa 1976) 25:596-601, 2000

18. Owens RK II, Crawford CH III, Djurasovic M, Canan CE, Burke LO, Bratcher KR, et al: Predictive factors for the use of autologous cell saver transfusion in lumbar spinal surgery. Spine (Phila Pa 1976) 38:E217-E222, 2013

19. Reitman CA, Watters WC III, Sassard WR: The Cell Saver in adult lumbar fusion surgery: a cost-benefit outcomes study. Spine (Phila Pa 1976) 29:1580-1584, 2004

20. Sharma S, Sharma P, Tyler LN: Transfusion of blood and blood products: indications and complications. Am Fam Physician 83:719-724, 2011

21. Stone N, Sardana V, Missiuna P: Indications and outcomes of Cell Saver in adolescent scoliosis correction surgery: a systematic review. Spine (Phila Pa 1976) 42:E363-E370, 2017

22. Weltert L, Nardella S, Rondinelli MB, Pierelli L, De Paulis $\mathrm{R}$ : Reduction of allogeneic red blood cell usage during cardiac surgery by an integrated intra- and postoperative blood salvage strategy: results of a randomized comparison. Transfusion 53:790-797, 2013

\section{Disclosures}

Dr. Carreon is an employee of Norton Healthcare, a consultant for AO Spine, and has received funds for travel from the University of Southern Denmark and the University of Louisville. She has received research funds from OREF, Norton Healthcare, Scoliosis Research Society (SRS), Pfizer, Integra, and IntelliRod (paid to her institution). She is a member of the Editorial Advisory Board for Spine, Spine Journal, and Spine Deformity; of the University of Louisville IRB; and of the Research Committee SRS. NuVasive provided funds directly to the database company. No funds are paid directly to the individual or the individual's institution. Dr. Crawford is a consultant for NuVasive and Medtronic, and he is an employee of Norton Healthcare. He receives clinical or research support for the study described (includes equipment or material) from Norton Healthcare. Dr. Dimar is a consultant for Medtronic and DePuy. He receives royalties from Medtronic. He is a board member of SRS and the Federation of Spine Associations, and he reviews for the Journal of the American Academy of Orthopedic Surgeons, Spine Deformity, Spine, and Global Spine. Dr. Djurasovic is a consultant for Medtronic and NuVasive. Dr. Glassman is an employee of Norton Healthcare. He holds a patent with Medtronic, as well as being a consultant and receiving royalties from that company. He is a past president of the SRS. Dr. Owens is a consultant for NuVasive and Medtronic.

\section{Author Contributions}

Conception and design: Carreon, Djurasovic. Acquisition of data: all authors. Analysis and interpretation of data: Carreon, Djurasovic, McGraw. Drafting the article: Djurasovic. Critically revising the article: all authors. Reviewed submitted version of manuscript: all authors. Approved the final version of the manuscript on behalf of all authors: Carreon. Statistical analysis: Carreon. Administrative/technical/material support: Carreon, McGraw, Bratcher. Study supervision: McGraw.

\section{Correspondence}

Leah Y. Carreon: Norton Leatherman Spine Center, Louisville, KY. leah.carreon@nortonhealthcare.org. 